\title{
Helix-loop-helix transcription factor E47 activates germ-line immunoglobulin heavy-chain gene transcription and rearrangement in a pre-T-cell line
}

\author{
Mark Schlissel, ${ }^{1}$ Anna Voronova, ${ }^{1}$ and David Baltimore \\ Whitehead Institute, Cambridge, Massachusetts 02142 USA; The Rockefeller University, New York, \\ New York 10021-6399 USA
}

E47 is a helix-loop-helix transcription factor that binds to sites in the immunoglobulin heavy-chain and $k$ light-chain gene enhancers. Other proteins of this type are involved in cell-type determination. A possible role for E47 in B-cell development was tested by overexpressing a cDNA encoding E47 in the pre-T-cell line 2017. We found a dramatic activation of a germ-line heavy-chain gene transcript in these stable transfectants and an equally large induction of immunoglobulin D-to-J rearrangement, the first recognized step in B-cell development. Germ-line $\kappa$ light-chain gene transcription and rearrangement were unaffected, but transcription of the recombination-activating genes RAG-1 and RAG-2 and the lymphoid-specific transcription factor Oct-2 was increased. These $T$ cells did not transcribe their rearranged $D J$ alleles, however, and failed to progress to the next stage of heavy-chain gene assembly, V-to-DJ rearrangement. Because transcription factor E47 can induce pre-T cells to carry out events of B-cell differentiation, it may be a crucial determinant of the earliest stages of B-cell development.

[Key Words: Immunoglobulin genes; B cells; development; gene rearrangement]

Received April 4, 1991; revised version accepted May 14, 1991.

Immunoglobulin and T-cell receptor (TCR) genes are generated during lymphoid development by an idiosyncratic, developmentally regulated series of somatic recombination events (Tonegawa 1983; Alt et al. 1987). Despite clear evidence for individual regulation of the seven sets of recombining gene segments, several lines of evidence support the idea that a single lymphoid recombinase catalyzes $\mathrm{V}(\mathrm{D}) \mathrm{J}$ recombination in both lineages. Highly homologous heptamer-nonamer recombination signal sequences (RSSs) flank both immunoglobulin and TCR genes (Tonegawa 1983). Rearrangement reporter constructs containing TCR RSSs rearrange upon transfection into pre-B cells (Yancopoulos et al. 1986), and transgenic immunoglobulin gene segments can rearrange in T cells (Ferrier et al. 1989; Ferrier et al. 1990). Finally, the recently cloned recombination-activating genes RAG-1 and RAG-2 are expressed in both pre-B and pre-T cells (Schatz et al. 1989; Oettinger et al. 1990).

Despite utilizing a common machinery, the various immunoglobulin gene rearrangement events are uniquely ordered during B-cell development (in the order heavy-chain D-to-J, V-to-DJ, and light-chain V-to-J rearrangement) and are largely restricted to the B-cell lineage

${ }^{1}$ These authors contributed equally to this work.
(Alt et al. 1987). It has been proposed that specific loci may be targeted for rearrangement by regulation of their accessibility to the recombinase machinery, perhaps through their transcriptional activation (Alt et al. 1987). Unrearranged immunoglobulin gene segments are transcribed in cells capable of undergoing immunoglobulin gene rearrangements (Van Ness et al. 1981; Reth and Alt 1984; Yancopoulos and Alt 1985; Schlissel et al. 1991). These germ-line transcripts may reflect the accessibility of a rearranging locus required to target the activity of the V(D)J recombinase (Alt et al. 1987).

The proteins that bind to immunoglobulin enhancers and may be involved in transcriptional activation of the recombination process include products of the E2A locus, especially the E47 protein. The DNA encoding E47 was cloned by virtue of the protein's affinity for a DNA sequence, E2, found in the immunoglobulin $\kappa$ lightchain $(\kappa E 2)$ and heavy-chain $(\mu \mathrm{E} 2$ and $\mu \mathrm{E} 5)$ enhancers (Murre et al. 1989). The protein contains the bHLH motif, a basic region, and an apparent helix-loop-helix structure also found in proteins, such as $\bar{m}$ yoD and achete-scute, which determine the developmental fate of specific cell types (Murre and Baltimore 1990). These proteins often form heterodimeric complexes, which may be the major forms found in cells (Murre and Baltimore 19901. 
Although it was originally found that E2A products are present in all cells (Murre et al. 1989), it later became evident that although the gene is widely transcribed, at least two types of control are exerted over the activity of the products. In some cells, such as muscle, E2A proteins are in heterodimers with other bHLH proteins (e.g., myoD) and no free, DNA-binding E2A products are evident (Murre et al. 1991). In other cells, E2A proteins are probably complexed with an inhibitor protein(s), such as Id, which has the HLH dimerization motif but no basic region and cannot bind to DNA (Benezra et al. 1990). In mature B cells, two unique DNA-binding forms of the E47 protein are evident (Murre et al. 1991). These apparently homodimeric E47 complexes, called BCF-1 and BCF-2, differ from one another in unknown ways and have not been seen in other cell types, leading to the suggestion that as a homodimer the E47 protein may be a B-cell-specific factor (Murre et al. 1991).

Previously, we examined the linkage between transcription and recombination by using lipopolysaccharide (LPS) to induce germ-line $\kappa$ light-chain gene transcription in cultured pre-B cells and showed that rearrangement of light-chain genes was induced in parallel (Schlissel and Baltimore 1989). In the present work, we provided a pre-T-lymphoma-cell line, 2017 (Spolski et al. 1988), with excess amounts of the transcription factor E47, and examined whether immunoglobulin heavychain gene transcription and rearrangement are induced. There is little or no germ-line transcription of the heavychain locus in 2017 cells, and they carry out only very rare D-to-J heavy-chain gene rearrangements (Schlissel et al. 1991). 2017 cells will, however, rearrange an immunoglobulin gene-based reporter construct (Lieber et al. 1987) and express relatively high levels of the recombination-activating genes RAG-1 and RAG-2 (Schatz et al. 1989; Oettinger et al. 1990).

We found dramatic increases both in the levels of a germ-line heavy-chain gene transcript and in the frequency of D-to-J rearrangements in E47-overexpressing 2017 cell transfectant clones. Furthermore, the levels of transcripts of three genes involved in lymphoid development, RAG-1, RAG-2, and Oct-2, were also increased. Interestingly, these transfected $\mathrm{T}$ cells did not progress to subsequent stages of B-cell development. We conclude that the E47 transcription factor is involved, either directly or indirectly, in the earliest events of differentiation that distinguish the B-cell and T-cell lineages, and that activation of the heavy-chain gene enhancer correlates with activation of the heavy-chain locus for D-to-J rearrangement.

\section{Results}

Expression of the E47 CDNA in 2017 pre-T cells

We placed the human $E 47$ cDNA into the CDM8 expression vector (Seed 1987) containing the neomycin resistance gene and electroporated the construct into the mouse pre-T-cell line 2017. As a control, we transfected these cells with the identical vector (termed neo-only) lacking the E47 gene. Cells were selected for G418 resistance, and stably transfected single-cell clones were generated by limiting dilution. We analyzed nine E47-containing transfectant clones and six neo-only control clones.

We assayed each clone for E47 expression by an RNA polymerase chain reaction (PCR) assay, by immunoprecipitation with anti-E47 antisera (Murre et al. 1991), and by electrophoretic mobility-shift analysis. The PCR assays were done on randomly primed first-strand cDNA. By limiting the number of amplification cycles and generating standards with serially diluted RNA templates (Fig. 1A, lanes labeled Undil., 1:5, 1:25, and 1:125), we were able to derive quantitative information. The E47 primers were designed to amplify a 385-nucleotide fragment from both mouse and human E47 RNAs, enabling us to assess the relative overexpression of this widely expressed RNA. Because the transfected cDNA is colinear with its RNA product and can therefore amplify in the PCR assay, we did assays with and without reverse transcriptase (Fig. 1A, lanes labeled + and - ) to show that the amplified fragment was dependent on reverse transcription of RNA. The PCR products were analyzed by Southern blot hybridization with radiolabeled E47 cDNA. Radioactivity was quantified, and the diluted control samples were used to generate a standard curve. We found an average 23 -fold increase in the amount of E47 RNA in the E47 transfectant clones as compared with the control clones (Fig. 1A,B). The levels of thymidine kinase (TK) (a gene product thought to be unaffected by E47 activity) gene RNA were assayed by PCR on the same cDNA preparations and did not vary significantly among the 15 clones (Fig. $1 \mathrm{C}, \mathrm{D})$.

These data agreed with both immunoprecipation and mobility-shift analyses, which revealed more E47 protein and specific DNA-binding activity in E47 transfectants than in controls (data not shown).

\section{E47 transfectants display markedly increased rates of immunoglobulin heavy-chain gene D-to-I rearrangement}

Occasional mature $\mathrm{T}$ cells have a D-to-J rearrangement at the immunoglobulin heavy-chain locus (Cory et al. 1980; Forster et al. 1980; Kemp et al. 1980). To determine whether E47 overexpression affects the frequency of DJ rearrangement in transfected as compared with control 2017 cell clones, we used a sensitive DNA PCR assay (Schlissel et al. 1991) (Fig. 2A). The assay used a degenerate $\mathrm{D}$ gene primer, which detects rearrangements involving 10 of the 11 known mouse $D$ genes, and a $J_{H}$ primer, which detects rearrangements to $\mathrm{J}_{\mathrm{H}} 1, \mathrm{~J}_{\mathrm{H}} 2$, or $\mathrm{J}_{\mathrm{H}} 3$, producing 1033-bp, 716-bp, or 333-bp amplified fragments that hybridize to a radiolabeled probe from the heavy-chain locus. By limiting the number of amplification cycles and utilizing standard templates with known concentrations of DJ alleles /the pre-B-cell line HAFTL has $\sim 1000$ rearrangements per 10,000 heavy-chain alleles; data not shown), the assay allows for quantitative comparisons of the frequencies of DJ alleles in various 


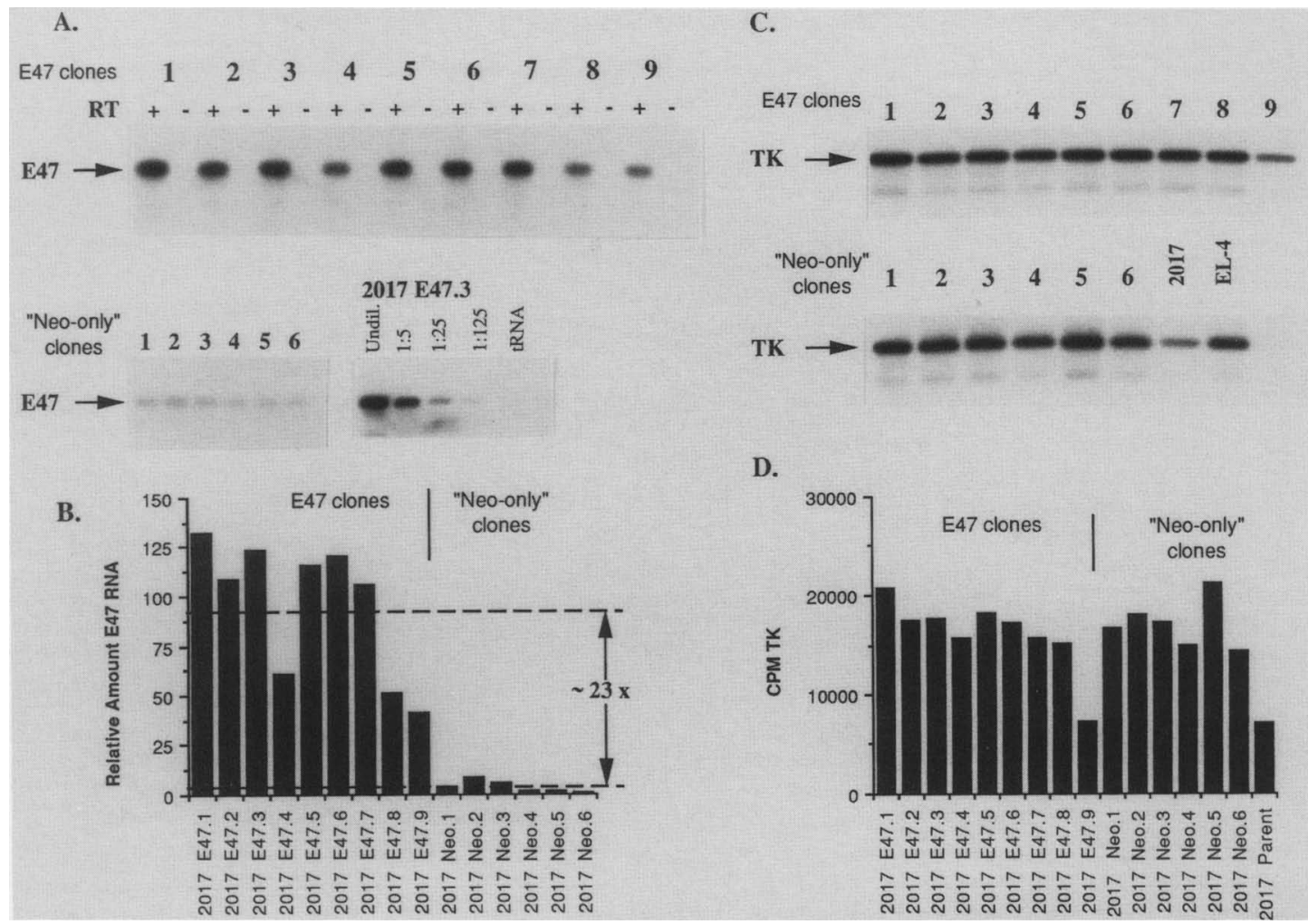

Figure 1. Expression of E47 RNA in transfectant and control 2017 cells. First-strand cDNA was synthesized with RNA from nine E47 transfectant clones and six neo-only clones. $(A)$ This cDNA was used for PCR amplification with primers recognizing both the endogenous (mouse) and transfectant (human) E47 genes, and the PCR products were detected by Southern blot hybridization with a radiolabeled E47 probe. An autoradiogram is shown, and the position of the E47 signal is indicated. The RNA from one clone, 2017 E47.3, was serially diluted into a tRNA carrier, analyzed similarly (lanes labeled Undil., 1:5, 1:25, and 1:125), and used to generate a standard curve. $(+$ and $-\mid$ cDNA synthesis reactions carried out with and without reverse transcriptase (RT), respectively (see text). (B) Specific radioactivity was determined with a Betagen analyzer; the calculated relative amounts of E47 RNA in the different clones are displayed graphically. $(C)$ The same cDNA as that used in $A$ was used in a PCR assay for TK gene transcription. The position of the TK-specific signal is indicated. $(D)$ TK-specific PCR signals were counted as described above and are displayed graphically.

cell populations. We found a striking (up to 150-fold) increase in the frequency of DJ rearrangement in the nine E47 transfectant clones as compared with the six control clones (Fig. 2B,C). Hence, E47 overexpression activated the earliest gene rearrangement step of B-cell development in this $\mathrm{T}$-cell line.

\section{E47 activates one class of germ-line heavy-chain gene transcript}

The heavy-chain enhancer contains two potential binding sites ( $\mu \mathrm{E} 2$ and $\mu \mathrm{E} 5)$ for E47 (Murre and Baltimore 1990). Because of the suggestion that transcriptional activation of germ-line immunoglobulin genes is a prerequisite for their rearrangement (Alt et al. 1987), we examined whether the overexpression of E47 affected germline heavy-chain gene transcription in the transfected clones. Two distinct germ-line heavy-chain gene transcripts, Mu0 and $\mathrm{I} \mu$ (Fig. 3A) (Lennon and Perry 1985; Schlissel et al. 1991), have been observed. Utilizing RNA PCR (Fig. 3A), we found an $\sim 80$-fold increase in the level of a transcript in the E47-expressing clones that has the properties of $\mathrm{I} \mu$ (Fig. 3B). This transcript starts heterogeneously $\sim 40$ bp $3^{\prime}$ of the octamer site in the enhancer (Lennon and Perry 1985) and was recently shown to use immunoglobulin heavy-chain enhancer elements as its promoter (Su and Kadesch 1990). We were unable to detect any transcriptional activation using a $5^{\prime}$ PCR primer hybridizing just upstream of the octamer site, suggesting that it is the $I \mu$ transcript that is induced /data not shown). We conclude from this result that $\mathrm{E} 47$ activates the I $\mu$ germ-line heavy-chain gene transcript, possibly by activating a promoter activity within the enhancer.

Previously, we had studied the Mu0 germ-line heavychain gene transcript, which initiates upstream of the most $\mathrm{J}_{\mathrm{H}}$-proximal $\mathrm{D}_{\mathrm{H}}$ gene segment and is appropriately spliced from $\mathrm{J}_{\mathrm{H}} 1$ to the first constant-region exon (Fig. 3A) (Allessandrini and Desiderio 1991; Schlissel et al. 1991). This transcript, which presumably depends on heavy-chain gene enhancer activity, previously was found in all tested pre-B cells that carry out D-to-J rearrangement in culture (Schlissel et al. 1991). To our surprise, RNA PCR analysis revealed that this transcript was unaffected by E47 overexpression (Fig. 3C). Hence, 
Figure 2. E47 overexpression activates immunoglobulin D-to-J rearrangement. (A) Diagram of the PCR assay used to detect DJ rearrangement. $\mathrm{V}_{\mathrm{H}}, \mathrm{D}_{\mathrm{H}}$, and $\mathrm{J}_{\mathrm{H}}$ are PCR primers. An example of a D- to $-\mathrm{I}_{\mathrm{H}} \mathrm{l}$ rearrangement is shown, but the sizes of PCR products from three possible DJ rearrangements are indicated. $(B)$ Autoradiogram of the blot hybridization of DJ rearrangement PCR assays on E47 and control transfectant clones showing the positions of DJ1, DJ2, and DJ3 amplification signals. DNA from the pre-B-cell line HAFTL was serially diluted into $3 \mathrm{~T} 3$ cell DNA and used to generate quantitative PCR standards. (Lane B1) The product of a PCR reaction without an added template; (lane $M$ ) markers. (C) Graphic representation of the number of DJ alleles per 10,000 genomes in transfectants and controls.

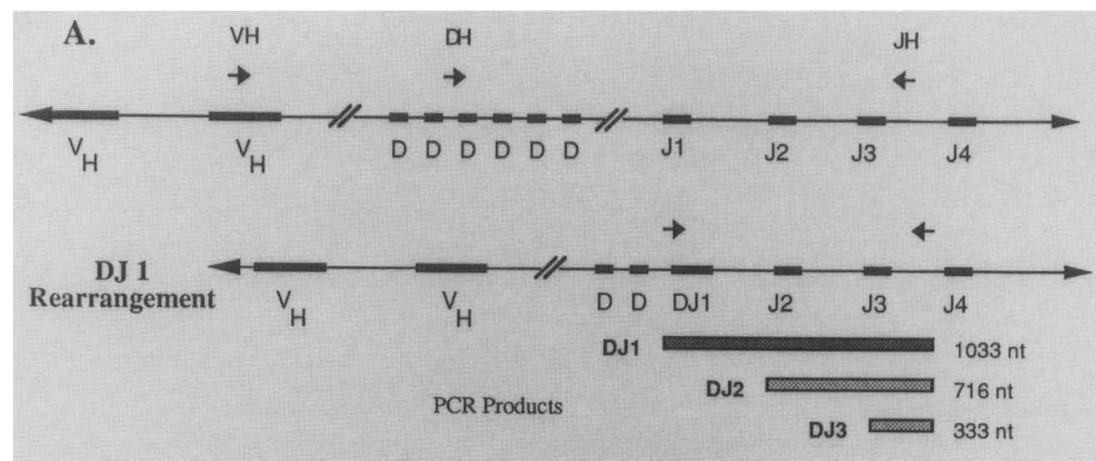

B.
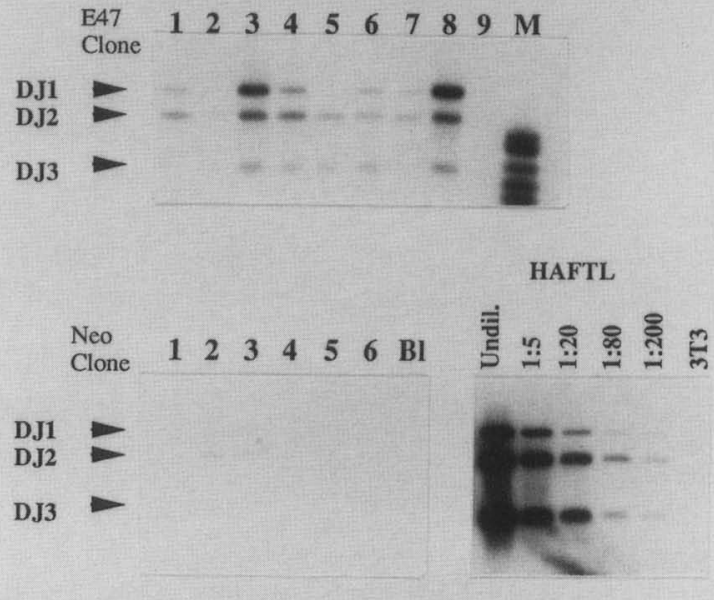

C.

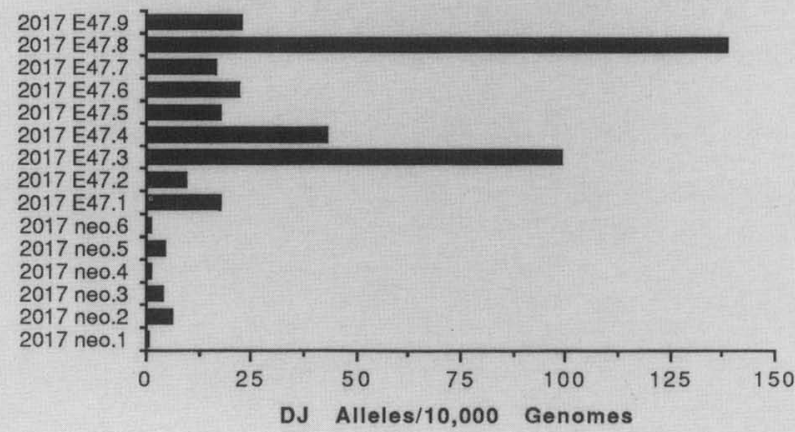

E47 activates only one of the germ-line transcripts in the vicinity of the immunoglobulin heavy-chain gene enhancer.

\section{E47 activates RAG-1, RAG-2, and Oct-2 gene transcription}

E47 overexpression might exert its effect on DJ rearrangement by activating the transcription of other genes possibly involved in the rearrangement of immunoglobulin genes. We assayed RNA from transfected 2017 cells for the levels of RAG-1 and RAG-2, two genes that act in synergy in the activation of rearrangement of an immunoglobulin gene reporter construct in fibroblasts (Oet- tinger et al. 1990), and Oct-2, a lymphoid-specific transcription factor with binding sites in the heavy- and light-chain gene enhancers and promoters (Lenardo et al. 1987; Staudt et al. 1988). We found that E47 overexpression resulted in either 3-fold (RAG-1; RAG-2 data were similar but are not shown) or 5.5-fold (Oct-2) increases in the expression of these lymphoid-specific genes (Fig. 4) . The levels of RAG-1 and RAG-2 RNAs were surprisingly high in all 2017 cell clones in light of the previous observation that this cell line rearranges an immunoglobulin reporter construct inefficiently as compared with cell lines such as HAFTL, which contain less RAG-1 and RAG-2 (Fig. 4A, lanes labeled HAFT1 and parent) (Lieber et al. 1987). In a preliminary set of experiments, overex- 


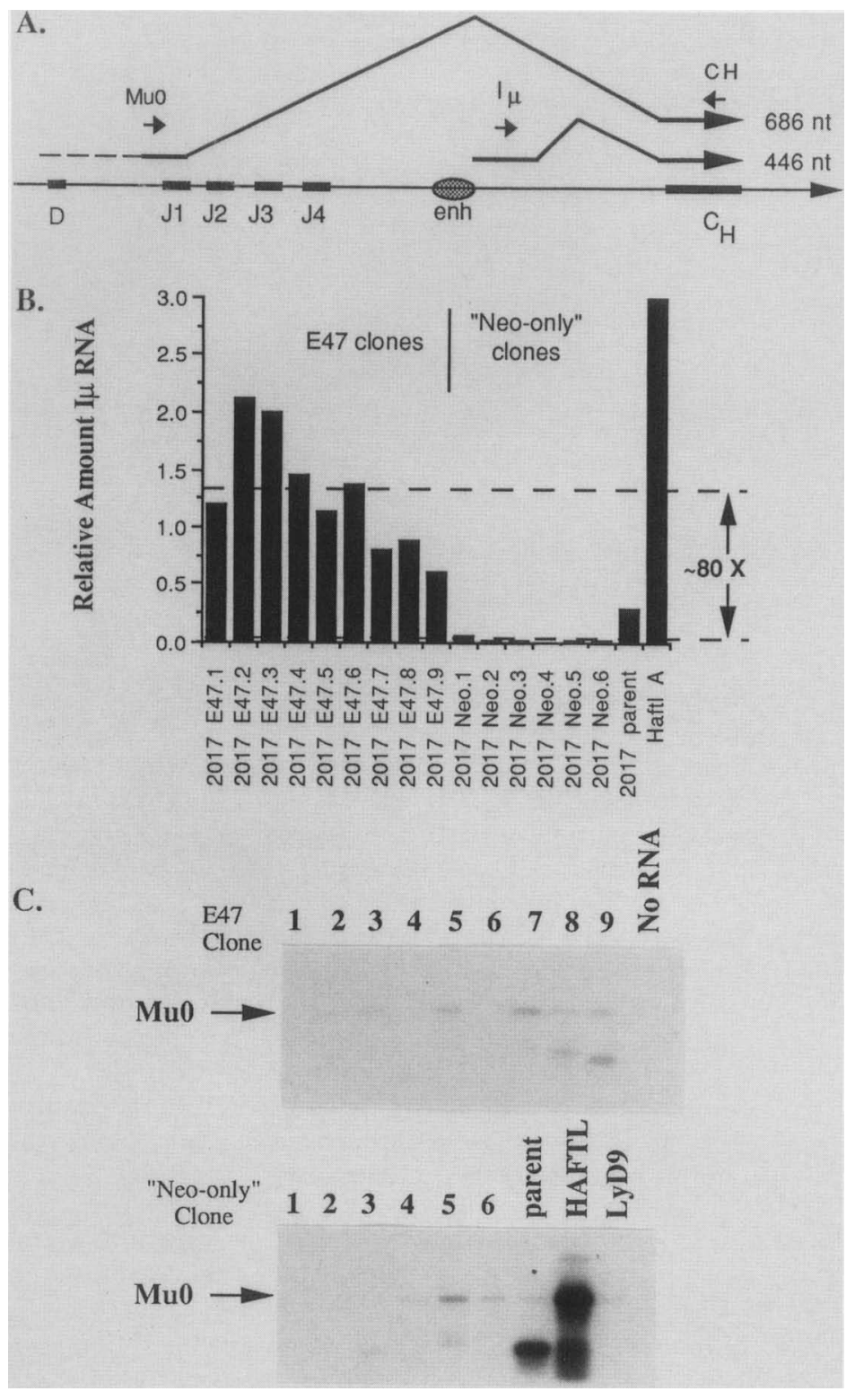

Figure 3. E47 activates germ-line heavy-chain gene transcription. (A) Diagram of the PCR assays used to detect germ-line transcription. The locations of the Mu0 and I $\mu$ transcripts and their splices are indicated, along with the positions of the PCR primers. (B) RNA PCR analysis of the $\mathrm{I} \mu$ transcript in E47 and control clones. RNA from transfectant E47.3 was serially diluted into a tRNA carrier and used in a PCR analysis to generate a standard curve. The standard curve was used to calculate the relative amounts of the I $\mu$ transcript in transfectants and controls, which are displayed graphically. The broken line indicates the average amount of I $\mu$ RNA in E47 transfectant and control clones. Parent represents the starting population of 2017 cells, and Haftl A is a pre-B-cell line actively engaged in D-to-J rearrangement. (C) RNA PCR analysis of the Mu0 transcript. The position of the Mu0 signal is indicated. LyD9 is a pro-B-cell line. pression of the Oct- 2 gene in 2017 cell clones did not activate the $\mathrm{I} \mu$ transcript or D-to-J rearrangement and therefore is probably not the sole mediator of E47 activation of germ-line immunoglobulin gene transcription (M. Schlissel, unpubl.).

\section{E47 does not activate germ-line $V_{H}$ or DJ gene transcription or VDI rearrangement}

Pre-B cells that carry out D-to-J rearrangement also carry out V-to-DJ rearrangement and actively transcribe both germ-line $\mathrm{V}_{\mathbf{H}}$ and partially rearranged DJ alleles (Schlissel et al. 1991). To determine whether E47-overexpressing 2017 cells could proceed to this next stage of B-cell development, we assayed the transfectants for DJ and $V_{H}$ transcription. Using sensitive RNA PCR assays, we were unable to detect any transcription of either the DJ alleles or the $\mathrm{V}_{\mathrm{H}}$ alleles in the three 2017 E47 transfectant clones with the highest levels of DJ rearrangement (Fig. 5 and data not shown) (Schlissel et al. 1991). By way of contrast, HAFTL RNA gave a readily detectable signal in both assays.

We also directly assayed the frequency of VDJ rearrangement in 2017 E47 clones 3 and 8 as compared with dilutions of HAFTL DNA containing similar numbers of DJ alleles (a necessary substrate for VDJ rearrangement) (Schlissel et al. 1991) (Fig. 6A). The assays used a mixture of degenerate $\mathrm{V}_{\mathrm{H}}$ primers capable of detecting rearrangement of a majority of the active $\mathrm{V}_{\mathrm{H}}$ gene repertoire. We were unable to detect any VDJ rearrangement in the E47overexpressing 2017 clones under conditions in which similar numbers of HAFTL DJ alleles showed obvious 
A.

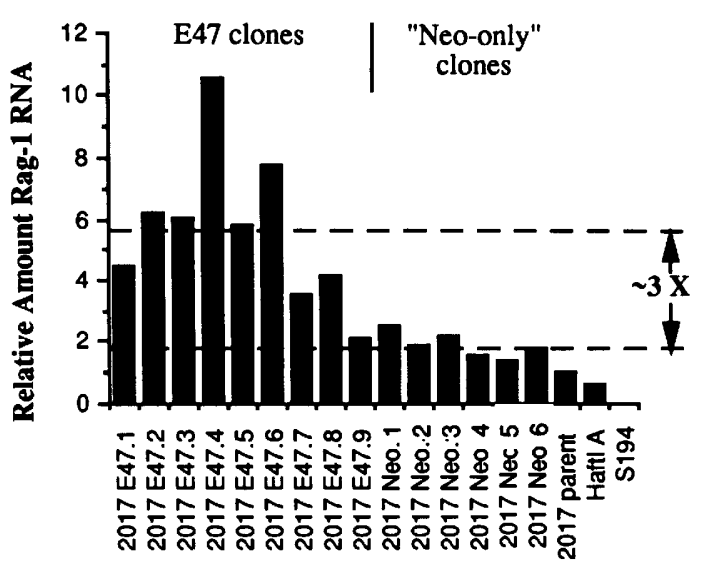

B.

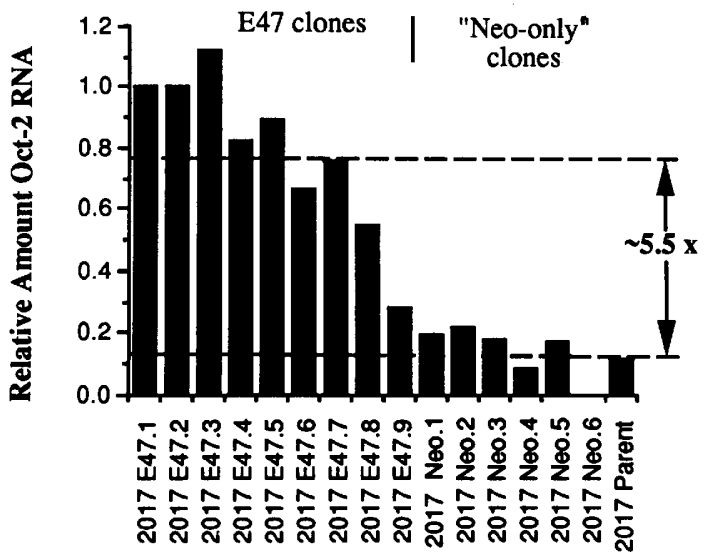

Figure 4. E47 activates RAG-1 and Oct- 2 transcription. (A) Graphic representation of RNA PCR analysis of RAG-1 transcription. Serially diluted 2017 E47.3 RNA served as a quantitative control. EL-4 is a mature T-cell line; S194 is a B-cell line. (B) Graphic representation of RNA PCR analysis of Oct-2 transcription. In $A$ and $B$, the broken lines indicate the average amounts of RNA in transfectants and controls.

VDJ rearrangements (Fig. 6B, lane labeled 400). Using previously described PCR assays (Schlissel and Baltimore 1989; Schlissel et al. 1991), we were likewise unable to detect $\kappa$ light-chain gene transcription or rearrangement in the E47 transfectants (data not shown). Furthermore, the E47 transfectants did not acquire expression of the B-cell lineage cell-surface markers B220 and Ia (data not shown).

\section{Discussion}

We have shown that stable overexpression of the cloned bHLH-class transcription factor E47 in a pre-T-cell line activates a germ-line immunoglobulin heavy-chain gene transcript and D-to-J rearrangement. The levels of three other lymphoid-specific gene transcripts (Oct-2, RAG-1, and RAG-2) were also increased. The cells did not, however, transcribe the rearranged DJ alleles or proceed to the next stage in pre-B-cell development, V-to-DJ rearrangement. We conclude that $\mathrm{E} 47$ can activate only the first gene rearrangement step of B-cell development and that further development requires additional factors.

\section{The role of HLH proteins in lymphoid development}

The ability of E47 to activate B cell-type gene transcription and rearrangement events suggests that $\mathrm{E} 47$ may be a B-cell differentiation factor despite its ubiquitous expression. In most other cells, heterodimerization with other active partners or with the inhibitory Id gene product presumably keeps E47 from forming homodimers (Benezra et al. 1990; Murre et al. 1991). We cannot unequivocally prove that in B cells there is no heteropartner for E47; it is the immunologic properties of the B-cell factor $(\mathrm{BCF})$ complexes that make them appear to be homodimers (Murre et al. 1991). It is possible that nontransfected 2017 cells are pre- $T$, and not pre-B, cells at least partially because there is normally little or no free E47 in these cells. 2017 cells contain high levels of Id gene transcripts relative to a variety of pre-B-cell lines (M. Schlissel, data not shown). Providing an excess of E47 may titrate Id and any other potential inhibitors, allowing active $\mathrm{E} 47$ homodimers to appear. In turn, they activate transcription and immunoglobulin gene rearrangement in these pre- $T$ cells. The induction of limited immunoglobulin gene transcription and rearrangement in these T cells by E47 is reminiscent of the induction of muscle lineage differentiation by myoD and related factors (Weintraub et al. 1991), and it is striking that myoD and E47 are both HLH proteins.

Whether E47 acts directly to stimulate rearrangement or activates some other gene that in turn stimulates D-to-J joining events is difficult to determine at present. We have shown that transcription of three other genes is stimulated. They are unlikely themselves to be responsible for activating D-to-J joining because RAG-1 and RAG-2 are already well-expressed in 2017 cells relative to actively rearranging pre-B-cell lines and are thought to be components of the basic recombination machinery, not specificity factors. Oct- 2 is a candidate activating factor, but our direct attempts to stimulate D-to-J rearrangement by overexpression of Oct- 2 have thus far been unsuccessful. Other mechanisms for E47-mediated activation are also conceivable-for instance, E47 may tie up Id and release some other activation factor that is ordinarily titrated by Id.

\section{Activation of the heavy-chain gene enhancer}

Overexpression of E47 had an unexpected effect on the transcription of the immunoglobulin heavy-chain locus: I $\mu$ but not $\mathrm{Mu} 0$ or DJ transcripts were stimulated. The characterized binding sites for E47 are in the heavy-chain enhancer, which is thought to activate lymphoid-specific transcription through the whole region. The en- 


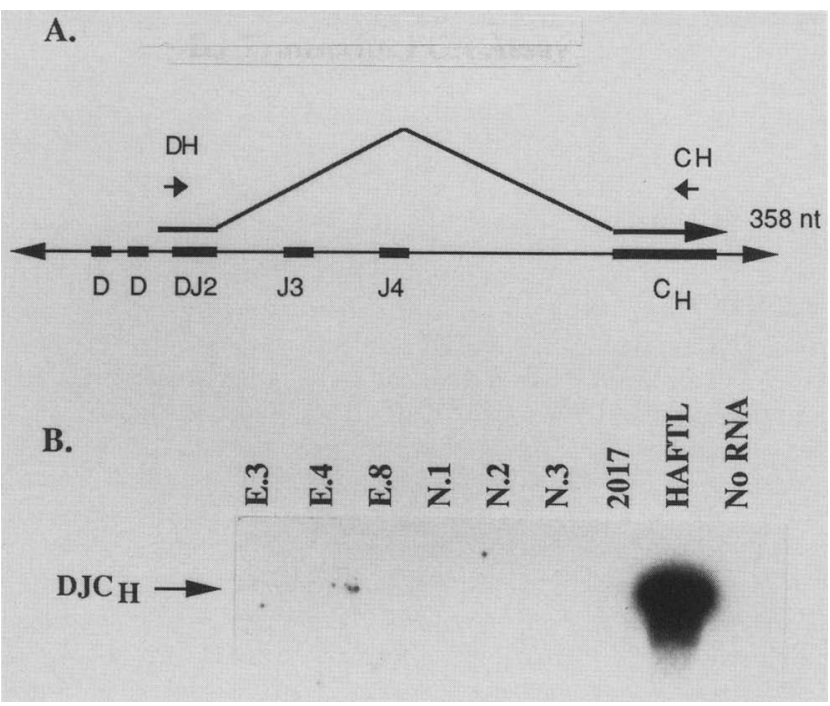

Figure 5. E47 transfectants do not transcribe their rearranged DJ alleles. (A) Diagram of the DJ transcript PCR assay. The transcript initiates upstream of the rearranged $D$ gene and is spliced to the first constant-region exon. The positions of PCR primers DH and $\mathrm{CH}$ are indicated. $(B)$ RNA PCR analysis of DJ transcription. E.3, E.4, and E.8 are the three 2017 E47 transfectant clones with the highest levels of DJ rearrangement. N.1, N.2, and N.3 are three neo-only 2017 control clones. 2017 is the parent cell line, and HAFTL is a transformed pre-B-cell line active in DI rearrangement.

hancer's action on functional fully rearranged heavychain genes is through the promoter in the $\mathrm{V}$ segment located several kilobases away, showing its ability to work effectively at a distance. The heavy-chain enhancer, however, contains binding sites for many proteins (at least three different E-box-binding proteins, Oct-2, $\mu \mathrm{B}, \pi$, and others; Liberman and Baltimore 1990). Although E47 stimulates Oct-2, providing at least these two factors, other factors may be absent. Therefore, the enhancer may not function in its usual way at a distance. The heavy-chain enhancer acts as the promoter for the I $\mu$ transcript, with Oct- 2 probably playing a key role because its binding site is just upstream of the initiation site of the transcript (Su and Kadesch 1990). Perhaps an incompletely occupied enhancer can activate as a promoter locally but not at a distance. An Oct-2-binding site alone can act as a B-cell-specific promoter (Wirth et al. 1987), and both E47 (A.Voronova, unpubl.) and ITF-1 (Ruezinsky et al. 1991), another product of the E2A locus closely related to E47, can trans-activate an E-box-dependent reporter construct in fibroblasts.

\section{Transcription and regulation of immunoglobulin heavy-chain gene rearrangement}

We have shown that E47 overexpression leads to activation of both immunoglobulin heavy-chain gene transcription and rearrangement. However, are the two events causally related? Specifically, does transcription lead to rearrangement? The question is not answerable by the type of experiments we performed, but the results do set some new limits on the relationship. The stimulated D-to-J rearrangement uses elements that are not part of the region through which the activated transcripts pass. Therefore, transcription does not stimulate rearrangement by making joining signals available for an interaction with recombinase as a consequence of RNA polymerase passage through the region. It would seem more likely that binding of the factor, not stimulated transcription, is the activating event. For instance, binding of E47 (possibly with Oct-2) could disrupt the local chromatin structure, making joining signals at some distance away more accessible to recombinase. Alternatively, the heavy-chain gene transcriptional enhancer might also be a recombination enhancer, directly inter-

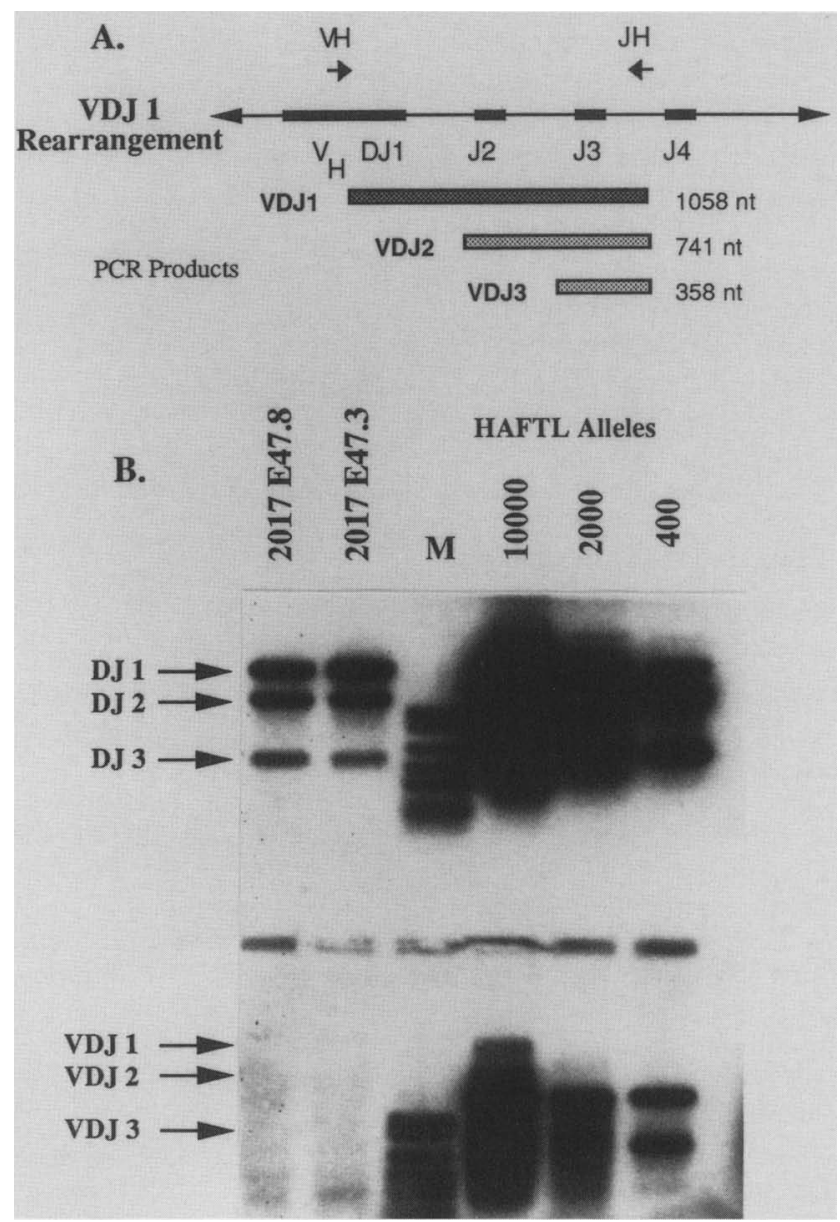

Figure 6. 2017 E47 transfectants do not activate V-to-DJ rearrangements. (A) Diagram of the PCR assay used to detect VDJ rearrangements. The positions of the degenerate $\mathrm{VH}$ primers and the JH primer are shown. $(B)$ DJ and VDJ rearrangement PCR assays. The DJ (upper) and VDJ (lower) assays were performed on two E47 transfectants and compared with serial dilutions of HAFTL DNA $(10,000,2000$, or 400 alleles). The autoradiogram is overexposed to highlight the absence of VDJ rearrangements in the E47 transfectants. $M$ is a marker. The positions of the various DJ and VDJ PCR products are indicated. 
acting with recombinase and serving to activate rearrangement at a distance. Finally, the $\mathrm{I} \mu$ transcript itself could have some direct role either in the rearrangement reaction or in its targeting.

It is interesting that E47 stimulates only D-to-J joining events and not V-to-DJ joining events. It appears that E47 can therefore begin the events of B-cell differentiation but that other factors are needed for events to progress. It is possible that the $\mathrm{E} 47$ homodimer is the natural activator of the beginning of B-cell differentiation. A decrease in the levels of Id is an early event in immunodifferentiation (M. Schlissel, data not shown). Progression of B-cell differentiation might involve secondary steps that cannot take place against the background of established T-cell differentiation in 2017 cells. In fact, germ-line heavy-chain gene transcription and D-to-J rearrangement naturally take place occasionally in T cells, possibly as a consequence of normal fluctuations in the relative levels of Id and E47. It is uncertain whether these D-to-J rearrangements occur before or after commitment of the precursor cell to the T-cell lineage. These D) alleles are sometimes transcribed in mature $\mathrm{T}$ cells, but heavy-chain protein is never produced, suggesting that there may be a dominant block to V-to-DJ rearrangement in T cells (Cory et al. 1980; Forster et al. 1980; Kemp et al. 1980). This idea is consistent with recent reports on the behavior of transgenic immunoglobulin gene rearrangement reporter constructs that carry out D-to-J but not V-to-DJ rearrangements in the T-cell lineage (Ferrier et al. 1989).

\section{Materials and methods \\ Cell lines and culture conditions}

The 2017 (Spolski et al. 1988) and EL-4 (mature T lymphoma) cells were obtained from Astar Winoto (Berkeley, CA), HAFTL cells (Alessandrini et al. 1987) were from Jacklyn Pierce (National Institutes of Health), LyD9 cells (Palacios et al. 1987) were from Ronald Palacios (Basel, Switzerland), and 3T3 cells were from Carolyn Gorka (Whitehead Institute). HAFTL and 2017 cells were grown in RPMI with $10 \%$ heat-inactivated fetal calf serum, $50 \mathrm{~mm}$ 2-mercaptoethanol, and antibiotics. LyD9 cells were grown in IMDM with $5 \%$ heat-inactivated fetal calf serum, 10\% WEHI-3 culture supernatant (a source of interleukin-3), and antibiotics. 3T3 cells were grown in Dulbecco's modified Eagle medium with $10 \%$ calf serum and antibiotics. All cells were maintained at $37^{\circ} \mathrm{C}$ in a humidified air- $-5 \% \mathrm{CO}_{2}$ incubator.

\section{Plasmid construction and electroporation of 2017 cells}

A 2-kb cDNA fragment containing the entire coding region of E47 was inserted into the BstXI site, and the neomycin resistance gene expressed from the PGK promoter was inserted into the BamHI site of the CDM8 vector (Seed 1987). 2017 cells (107) in ice-cold PBS were added to $20 \mu \mathrm{g}$ of linearized plasmid in an electroporation cuvette (Bio-Rad). Electroporation was carried out with a Gene Pulser (Bio-Rad) at $240 \mathrm{~V}$ and $960 \mu \mathrm{F}$. Cells were grown for $24-36 \mathrm{hr}$ in normal medium, after which time the medium was replaced with medium containing $1.5 \mathrm{mg} / \mathrm{ml}$ of G418 (GIBCO). G418-resistant cells were cloned by limiting dilution ( 0.3 cells per well $)$ in drug-containing medium. Usually, 10-15 wells from a 96-well plate contained colonies after 10-14 days of growth.

\section{RNA PCR assays}

RNA was purified by the guanidinium method (Ausubel et al. 1987) from actively growing cell cultures and was resuspended in DEPC-treated water at $1 \mathrm{mg} / \mathrm{ml}$. Randomly primed cDNA was synthesized from $3 \mu \mathrm{g}$ of total RNA as described previously (Schlissel et al. 1991) and diluted to a final volume of $50 \mu$ l with water. Comparative analyses were performed on cDNAs synthesized simultaneously. PCR assay mixtures (Saiki et al. 1988) consisted of $2 \mu \mathrm{l}$ of cDNA in a 50- $\mu$ l reaction mixture containing $10 \mathrm{~mm}$ Tris (pH 8.5) (at room temperature), $2.0 \mathrm{~mm} \mathrm{MgCl}_{2}$, $50 \mathrm{~mm} \mathrm{KCl}, 50 \mathrm{ng}$ of each oligonucleotide primer, $100 \mu \mathrm{g} / \mathrm{ml}$ of BSA, and 1 unit of Amplitaq (PE-Cetus). Amplifications were done with a PE-Cetus DNA thermal cycler for 22-26 cycles, with each cycle consisting of $1 \mathrm{~min}$ at $94^{\circ}, 1 \mathrm{~min}$ at $60^{\circ}$, and 2 $\min$ at $72^{\circ}$, followed by an additional $10 \mathrm{~min}$ at $72^{\circ}$. One-fifth of each reaction mixture was separated on an agarose gel, blotted in $\mathrm{NaOH}$ to Zetabind (AMC), and hybridized with OLB-labeled (Feinberg and Vogelstein 1983) gene-specific probes. The radioactivity in each specific amplified product was quantified directly with a Betagen analyzer. Quantitative standards were generated by diluting amounts of the standard RNA into water containing either tRNA or RNA from a cell type lacking the transcript to be assayed and subjecting the samples to both cDNA synthesis and PCR in parallel with test samples. These standards were used to calculate the relative amounts of target RNAs in each of the assays. All RNA PCR assays, with the exception of the E47 assay done on E47 transfectants, used oligonucleotide pairs that crossed intron-exon boundaries; hence, DNA contamination could not account for the specific PCR signal. Control assays done without reverse transcriptase were performed on the E47 transfectant clones to control for DNA contamination. Autoradiograms were exposed at room temperature without intensifying screens.

\section{DNA PCR}

Heavy-chain gene rearrangement PCR assays were done on crude lysates of carefully counted numbers of cells as described previously (Schlissel and Baltimore 1989; Schlissel et al. 1991). Amplification conditions were identical to those used for RNA PCR ( 25 cycles), and analysis was likewise done by blot hybridization and Betagen counting. HAFTL control templates were diluted into standard amounts of 3T3 cell lysate.

\section{Sequences of PCR oligonucleotides}

All oligonucleotides were synthesized on an Applied Biosystems model 391 DNA synthesizer and used without further purification. The $\mathrm{D}_{\mathrm{H}}, \mathrm{I}_{\mathrm{H}}, \mathrm{C}_{\mathrm{H}}, \mathrm{V}_{\mathrm{H}}, \mathrm{Mu0}, \mathrm{RAG}-1$, and RAG-2 PCR oligonucleotides were described previously (Schlissel and Baltimore 1989; Chun et al. 1991; Schlissel et al. 1991). The other oligonucleotide sequences were as follows:

OCT L, TCAACAAACCCAGGGAGCTCTCCTG; OCT R, AACTCTTCTCTAAGGCGAAGCGGAC; TK L, GTGCTAACTAAGGTTTGCACAGCAG; TK R, GAGGCAAAGAGCTTCCTGACAACC; $\mathbf{I} \boldsymbol{\mu}$, ACCTGGGAATGTATGGTTGTGGCTT; MHE-1, CTCCCGACTCCTA(C/T)AGTGG(A/G)CT(C/ A)GG; and MHE-2, TCCGCTCTCGCACCTGCTGCTCCAG. 


\section{Acknowledgments}

We thank David Schatz and Lynn Corcoran for helpful comments on the manuscript and David Schatz for the gift of RAG gene PCR oligonucleotides. M.S. acknowledges the support of a Bristol-Myers Cancer Research Fellowship. A.V. was supported by fellowships from the American Cancer Society and the Cancer Research Institute. This work was supported by U.S. Public Health Service grant GM 39458.

The publication costs of this article were defrayed in part by payment of page charges. This article must therefore be hereby marked "advertisement" in accordance with 18 USC section 1734 solely to indicate this fact.

\section{References}

Alessandrini, A. and S.V. Desiderio. 1991. Coordination of immunoglobulin $\mathrm{DJ}_{\mathrm{H}}$ transcription and D-to- $\mathrm{J}_{\mathrm{H}}$ rearrangement by promoter-enhancer approximation. Mol. Cell. Biol. 11: 2096-2107.

Alessandrini, A., J.H. Pierce, D. Baltimore, and S.V. Desiderio. 1987. Continuing rearrangement of immunoglobulin and T-cell receptor genes in a Ha-ras-transformed lymphoid progenitor cell line. Proc. Natl. Acad. Sci. 84: 1799-1803.

Alt, F., T. Blackwell, and G. Yancopoulos. 1987. Development of the primary antibody repertoire. Science 238: 1079-1087.

Ausubel, F., R. Brent, R. Kingston, D. Moore, J. Seidman, J. Smith, and K. Struhl. 1987. Current protocols in molecular biology. Greene/Wiley, New York.

Benezra, R., R.L. Davis, D. Lockshon, D.L. Turner, and H. Weintraub. 1990. The protein Id: A negative regulator of helixloop-helix DNA binding proteins. Cell 61: 49-59.

Chun, J.M., D.G. Schatz, M.A. Oettinger, R. Jaenisch, and D. Baltimore. 1991. The recombination activating gene-1 (RAG-1) transcript is present in the murine central nervous system. Cell 64: 189-200.

Cory, S., J.M. Adams, and D.J. Kemp. 1980. Somatic rearrangements forming active immunoglobulin $\mu$ genes in $\mathrm{B}$ and $\mathrm{T}$ lymphoid cell lines. Proc. Nat1. Acad. Sci. 77: 4943-4947.

Feinberg, A.P. and B. Vogelstein. 1983. A technique for radiolabeling DNA restriction endonuclease fragments to high specific activity. Anal. Biochem. 132: 6-13.

Ferrier, P., B. Krippl, A.J. Furley, T.K. Blackwell, H. Suh, M. Mendelsohn, A. Winoto, W.D. Cook, L. Hood, F. Costantini, and F.W. Alt. 1989. Control of VDJ recombinase activity. Cold Spring Harbor Symp. Quant. Biol. 54: 191-202.

Ferrier, P., B. Krippl, T.K. Blackwell, A. Furley, H. Suh, A. Winoto, W.D. Cook, L. Hood, F. Costantini, and F.W. Alt. 1990. Separate elements control DJ and VDJ rearrangement in a transgenic recombination substrate. $E M B O J$. 9: 117125

Forster, A., M. Hobart, H. Hengartner, and T. Rabbitts. 1980. An immunoglobulin heavy-chain gene is altered in two T-cell clones. Nature 286: 897-899.

Kemp, D., A. Harris, S. Cory, and J. Adams. 1980. Expression of the immunoglobin $\mathrm{C} \mu$ gene in mouse $\mathrm{T}$ and $\mathrm{B}$ lymphoid and myeloid cell lines. Proc. Natl. Acad. Sci. 77: 2876-2880.

Lenardo, M., J.W. Pierce, and D. Baltimore. 1987. Protein-binding sites in immunoglobulin gene enhancers determine transcriptional activity and inducibility. Science 236: 15731577.

Lennon, G.G. and R.P. Perry. 1985. C mu-containing transcripts initiate heterogeneously within the $\mathrm{IgH}$ enhancer region and contain a novel 5'-nontranslatable exon. Nature 318: 475478.

Liberman, T.A. and D. Baltimore. 1991. Transcriptional regula- tion of immunoglobulin gene expression. In Hormonal regulation of transcription (ed. P. Cohen and J.G. Foulkes), pp. 385-407. Elsevier-Biomedical, Amsterdam.

Lieber, M., J. Hesse, K. Mizuuchi, and M. Gellert. 1987. Developmental stage specificity of the lymphoid V(D)J recombination activity. Genes \& Dev. 1: 751-761.

Murre, C. and D. Baltimore. 1990. The helix-loop-helix motif: Structure and function. In Transcriptional regulation (ed. K. Yamamoto and S. McKnight), Cold Spring Harbor Laboratory Press, Cold Spring Harbor, New York.

Murre, C., P.S. McCaw, and D. Baltimore. 1989. A new DNA binding and dimerization motif in immunoglobulin enhancer binding, daughterless, $\mathrm{MyoD}$ and myc proteins. Cell 56: $777-783$.

Murre, C., A. Voronova, and D. Baltimore. 1991. B-cell and myocyte-specific E2-box binding factors contain E12/E47-like subunits. Mol. Cell. Biol. 11: 1156-1160.

Oettinger, M.A., D.G. Schatz, C. Gorka, and D. Baltimore. 1990. RAG-1 and RAG-2, adjacent genes that synergistically activate $V(D))$ recombination. Science 248: 1517-1523.

Palacios, R., H. Karasuyama, and A. Rolink. 1987. Lyl + pro-B lymphocyte clones. Phenotype, growth requirements and differentiation in vitro and in vivo. EMBO J. 6: 3687-3693.

Reth, M. and F. Alt. 1984. Novel immunoglobulin heavy-chains are produced from $\mathrm{DJ}_{\mathrm{H}}$ gene segment rearrangements in lymphoid cells. Nature 312: 418-423.

Ruezinsky, D., H. Beckmann, and T. Kadesch. 1991. Modulation of the $\operatorname{IgH}$ enhancer's cell type specificity through a genetic switch. Genes \& Dev. 5: 29-37.

Saiki, R., D. Gelfand, S. Stoffel, S. Scharf, R. Higuchi, G. Horn, K. Mullis, and H. Erlich. 1988. Primer-directed enzymatic amplification of DNA with a thermostable DNA polymerase. 239: 487-494.

Schatz, D.G., M.A. Oettinger, and D. Baltimore. 1989. The V(D)J recombination activating gene, RAG-1. Cell 59: 1035-1048.

Schlissel, M. and D. Baltimore. 1989. Activation of immunoglobulin kappa gene rearrangement correlates with induction of germline kappa gene transcription. Cell 58: 10011007.

Schlissel, M.S., L.M. Corcoran, and D. Baltimore. 1991. Virallytransformed pre-B cells show ordered activation but not inactivation of immunoglobulin gene rearrangement and transcription. I. Exp. Med. 173: 711-720.

Seed, B. 1987. An LFA-3 cDNA encodes a phospholipid-linked membrane protein homologous to its receptor CD2. Nature 329: $840-842$.

Spolski, R., G. Miescher, R. Erard, R. Risser, H.R. MacDonald and T.W. Mak. 1988. Regulation of expression of T cell gamma chain, L3T4 and Ly-2 messages in Abelson/Moloney virus-transformed T cell lines. Eur. I. Immunol. 18: 295300

Staudt, L.M., R.G. Clerc, H. Singh, J.H. LeBowitz, P.A. Sharp, and D. Baltimore. 1988. Cloning of a lymphoid-specific cDNA encoding a protein binding the regulatory octamer DNA motif. Science 241: 577-580.

Su, L.-K. and T. Kadesch. 1990. The immunoglobulin heavychain enhancer functions as the promoter for I mu sterile transcription. Mol. Cell. Biol. 10: 2619-2624.

Tonegawa, S. 1983. Somatic generation of antibody diversity. Nature 302: $575-581$.

Van Ness, B., M. Weigert, C. Coleclough, E. Mather, D. Kelley, and R. Perry. 1981. Transcription of the unrearranged mouse $C_{\kappa}$ locus: Sequence of the initiation region and comparison of activity with a rearranged $V_{\kappa}-C_{\kappa}$ gene. Cell 27: 593-602.

Weintraub, H., R. Davis, S. Tapscott, M. Thayer, M. Krause, R. Benezra, T.K. Blackwell, D. Turner, R. Rupp, S. Hollenberg, 
Schlissel et al.

Y. Zhuang, and A. Lassar. 1991. The myoD gene family: Nodal point during specification of the muscle cell lineage. Science 251: 761-766.

Wirth, T., L. Staudt, and D. Baltimore. 1987. An octamer oligonucleotide placed upstream of a TATA motif is sufficient for lymphoid-specific promoter activity. Nature 329: 174177.

Yancopoulos, G. and F. Alt. 1985. Developmentally controlled and tissue-specific expression of unrearranged $\mathrm{V}_{\mathrm{H}}$ gene segments. Cell 40: 271-281.

Yancopoulos, G., T. Blackwell, H. Suh, L. Hood, and F. Alt. 1986. Introduced $T$ cell receptor variable region gene segments recombine in pre-B cells: Evidence that $B$ and $T$ cells use a common recombinase. Cell 44: 251-259. 


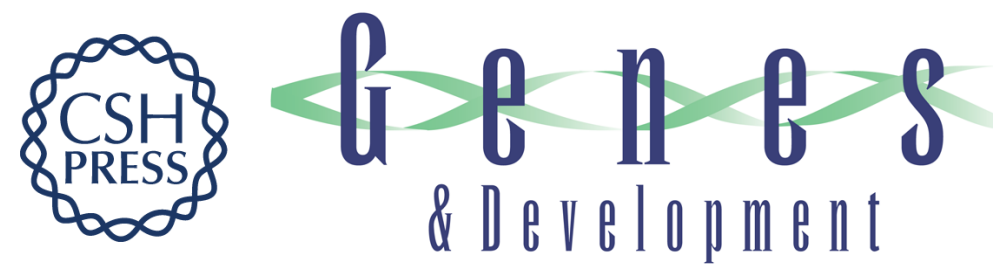

\title{
Helix-loop-helix transcription factor E47 activates germ-line immunoglobulin heavy-chain gene transcription and rearrangement in a pre-T-cell line.
}

\author{
M Schlissel, A Voronova and D Baltimore
}

Genes Dev. 1991, 5:

Access the most recent version at doi:10.1101/gad.5.8.1367

$\begin{array}{ll}\text { References } & \text { This article cites } 33 \text { articles, } 15 \text { of which can be accessed free at: } \\ \text { http://genesdev.cshlp.org/content/5/8/1367.full.html\#ref-list-1 }\end{array}$

License

Email Alerting Receive free email alerts when new articles cite this article - sign up in the box at the top Service right corner of the article or click here.

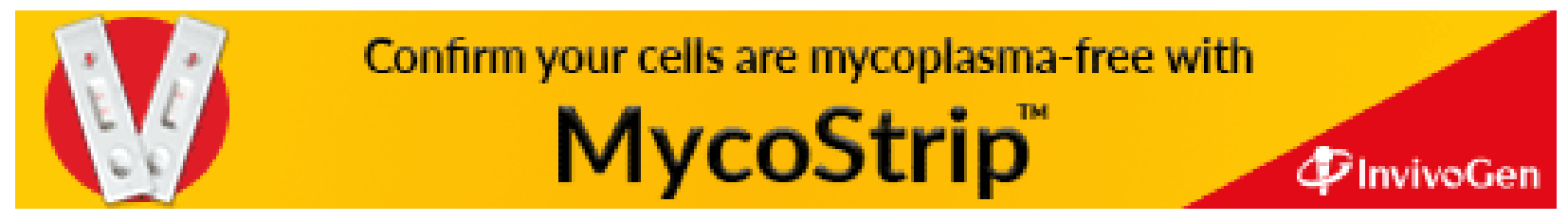

